and $I$ am sorry $I$ can only designate this allegation as a deliberate untruth. Further, I would beg him to remember that the mere repetition of an untruth cannot (as he seems to fancy) betimes convert it into a truth.

I shall neither weary you nor myself by refuting, as $I$ intended, some of "Irons" other studied misrepresentations and mis-statements. Let me only revert to one more. Among other matters of blame, "Irons" states, that to me, "more than any other individual, we are indebted for the profligate use of the speculum," and for "pessaries which have justly been designated infernal and impaling uterine machines." The first of these accusations I utterly and indignantly deny. The essays that have appeared upon uterine disease, in the pages of The Lavcet, have, I know, done more than any other English writings to spread the use of the speculum in Britain; and neither in THE LANCET, nor elsewhere, have I, at least, ever written in its favour. In fact, I have always held and taught, that by the advocates of the speculum, greatly too much was expected from its employment; and that it was often had recourse to in cases and diseases in which it was entirely uncalled-for, because it was entirely useless. Among the various patients whom I have at the present moment here under my charge from London, five ont of the number are, or were, the subjects of aggravated retroversion. In all of these cases the speculum had been employed in London-in three, properly, because there were, in them, inflammatory lesions to treat; but in the other two, improperly, as $I$ conceive, because the instrument was unnecessary as a means of diagnosis. One of these last two patients was a patient of "Irons" himself. For some weeks during the last autumn she wore an "infernal and impaling" intra-uterine pessary, with complete relief to the symptoms under which she had been suffering for years. After the instrument was for some time finally withdrawn, she for the first time told me that she had previonsly consulted "Irons," who informed her, as I had done, that her disease was retroversion; that he recommended her to use a pessary, but advised the pessary to be withdrawn and re-introduced once or twice daily; that (though he has declaimed so much against the speculum, and though the speculum was assuredly not required in this, a mere instance of uncomplicated retroversion) he insisted upon employing it; that when she objected to its use, he and a medical friend who was with him argued that it was required " a thousand times a day;" that in using it, he placed her upon a common drawing-room sofa; and that altogether (although she has now seen several obstetricians) his questions and examination were, she declares, more indelicate and painful than any others to which she has ever been subjected. Dr. Duffin, of Langham-place, knows the case I refer to.

In the last number of THE LANCET, in your Notes to Corre. spondents, you adduce the following as a kind of reason for admitting into your pages such letters and attacks upon me as that written by "Irons." "Dr. Simpson," you observe, "will not fail to recollect that his name is systematically published as that of one of the editors (conductors) of the Edinburgh Monthly Journal of Medical Science, a work which habitually contains very gross imputations on the reputation and conduct of the hospital physicians and surgeons of this metropolis. In consequence of not having repelled such attacks, we have been accused of exercising undue forbearance, and even of showing culpable partiality towards Dr. Simpson and his colleagues of the northern journal." The journal in question was assumed by its present conductors principally with a view of promulgating the doctrines of the Edinburoh Medical Sehool, and of defending these doctrines from the mis-statements to which they were systematically subjected in your own and in other journals. For instance, from "culpable partiality," (?) you admitted years ago into your own pages various anonymons letters from "Irons" and others (or rather, I should probably say, from "Irons" under various other names), containing attacks and misrepresentations regarding myself and my practice, nearly as unprincipled and as violent as that which has just appeared in THE LANCET. Since becoming one of the proprietors and conductors of the Monthly Journal, I can honestly declare that I have never-written one single word of blame or imputation against any London medical man. You must excuse me, however, for adding, that after what has happened, I do not pledge myself to be equally lenient for the future.

In my previous letter to you I mentioned that I was informed by one of your first surgeons in London that " he was attending the foot of a noble duke, whilst a celebrated homoopathist was attending to his grace's stomach and constitution." In your last number $I$ am urged by one of your correspondents "to state fairly and openly the name of this surgeon." But the surgeon in question told me this circumstance in the course and confidence of private conversation; and I could not but view myself as breaking through every rule of good faith if I complied with your correspondent's request.

$$
\begin{aligned}
& \text { Edinburgh, Sept. 29, } 1851 . \\
& \hline
\end{aligned}
$$

\section{TREATMENT OF DIARRHEA BY SULPHURIC ACID ALONE.}

To the Editor of THE LANCET.

Sir,-I beg to send you a few of the cases which I have attended, and in which I have witnessed the most marked effects of the diluted sulphuric acid administered alone in diarrhcea. I would here call the attention of your numerous readers to the fact of this remedy having been recommended by the late Dr. Anthony Todd Thompson in diarrhœas. In the "London Dispensatory" of 1837 , page 762 , there is an article on the Diluted Sulphuric Acid, in which he states, "that when combined with mucilages, it has been beneficially given in passive diarrhceas, operating on the relaxed nervous coat of the intestine as an astringent. The usual dose is from ten to thirty minims, but this dose may be very often repeated."

I hope, Sir, that the publication of the following cases may be the means of inducing others to try this invaluable agent in cholera and diarrhœa, and report the result of their observations in your widely-circulated journal.

Allow me to remark, that sulphuric acid varies in quality, purity, specific gravity, and price, and therefore care should be taken in its selection. My mode of prescribing it for an adult is to give half a drachm of the diluted acid (P. L.) in ten drachms of water, for the first dose, and to continue twenty minims after every loose stool.

I am, Sir, your obedient servant,

Eaton-square, Sept. 1851.

Wildidam Griffith.

CASE 1.-John G-—, No.6, Belgrave-buildings, aged fortyeight, was seized on Sunday evening, the 24th of August, with violent vomiting and purging, attended with great pain in the bowels. Pulse weak, skin cold, and countenance very pallid. Ordered to bed, and to take half a drachm of diluted sulphuric acid (P. L.) in ten drachms of water. When I called at his house early on Monday morning, his wife informed me that he was quite well, and had gone to work.

CASE 2.-Charles P- was desired to come to me on Friday, the 29th August, by the Rev. Mr. Brown, of Halkin. street. He was labouring under diarrhcea, which had been going on for some weeks. Gave him one dose similar to the above, and told him to come the next day if not relieved. He did not call until Sunday morning, when he stated there had been no action of the bowels since he swallowed the acid. Has not called again.

CASE 3.-Charles B-, aged twenty-two, came to my house on Sunday evening, the 31st of August. Complained of vomiting and purging. The diarrhcea had been going on for four days. Gave him half a drachm of the acid in water, with orders to come again if necessary. Up to the time of writing this account I have not heard from him.

CASE 4.-Ellen J-C, aged twenty-four, of No. 8, Eatoncourt, consulted me on the 4 th of September. Had diarrhcea thirty hours, with considerable pain in the bowels, and nausea. Had twelve motions during the last four hours. She had a mixture, with two drachms of the acid in six ounces of water, with directions to take three tablespoonfuls directly, and two tablespoonfuls after every loose stool.

Sept. 5th.- Had five motions in the last twenty-four hours. Free from pain and nausea. Medicine to be continued.

6th.-Bowels regular. Discharged cured.

CASE 5.-Elizabeth W-, aged forty, living at No. 5, Belgrave-buildings, came to me on the 4 th of September. Diarrhoea two days, with griping pains; vomiting. and headache. Ordered her the acid as in the other cases.

Sept. 5th.-Much relieved.

6th.-Cured.

CASE 6.-Thomas L—, aged seven, of No. 8, Eaton-court, was seen by me on the 4 th of September. Had diarrhœa two days. Prescribed for him-Diluted sulphuric acid, twenty. five minims; water, four ounces. Mix. One large spoonful to be taken after every loose stool. He took three doses, and is perfectly well.

CASE 7.-J. Wbuildings, had vomiting and purging of a severe nature, 
attended with pain in the bowels. These symptoms yielded to half a drachm of the acid.

CASE 8.--During the night of Saturday last, I was called ont of bed to a lady in Wilton-street, whom I have attended for many years. I found her in a state of great agony, suffering from violent spasms in the bowels, constant vomiting, great prostration, with diarrhoea of three days' standing. II gave her half a drachm of the diluted acid in water, and sat at her bed-side for two hours, when I left her, free from pain and sickness.

I saw her on Sunday morning, at ten. There had been no vomiting; neither had she had one motion since she had taken the acid, but she complained of nausea. Ordered her twenty minims of the acid. I saw her in the evening, at seven. There had been one comfortable evacuation; pulse improved; tongue clean; nausea subsided.

At my morning visit, I was consulted by her daughter, a young lady, aged seventeen, who was (after I had left her mother in the night) attacked with vomiting and purging, attended with griping pains. I gave her twenty minims of the acid, with directions to repeat it if necessary. At my visit at seven in the evening, I found the vomiting had quite ceased, and there had been no action of the bowels after taking the above dose. The patient was free from pain.

Monday morning: Mother and daughter perfectly free from diarrhœa, pain, vomiting, and nausea. Directed the acid to be discontinued.

\section{E D C A L A S ISTA NTS. To the Editor of THE LANCET.}

SIn,-I am an assistant, under peculiar circumstances, of several years' standing. I, therefore, have had opportunities to "practise the eye," attune the ear, educate the finger, and see disease in nearly all its varied forms.

I have also been "taught the difficult art of doing nothing," learned how to handle "the six divine remedies," and am enabled to bear my humble testimony to the general excel. lency of the remarks of Mr. Spong in The LANCET of the 13th September.

I am sorry, however, that he contributes his mite to the "unhappy comparisons" which have been made regarding the salaries of medical assistants. True, the majority of practices, as he says, are neither extensive nor profitable; yet he forgets that the majority of practices which require the aid of assistants, are calculated to remunerate to a larger extent than they really do, the tear and wear, anxiety and excitement, which are the daily and nightly attendants on the life of this class of individuals.

"Thirty or forty pounds" is a wretched sum to offer an educated person for the capital which has been expended in acquiring the knowledge requisite to enable him to enter upon such important duties; -why, it is not common interest for the money, neither is it sufficient to enable him to sustain that self-respect and gentlemanly deportment, which are at all times essential when called on to supply the place of the principal in his absence. Although the salary of the assistant has increased twenty per cent. during the last five years, still there is much room for improvement. The profession ought to bear in mind, that low salaries have done more to drive assistants into low habits and low company than many practitioners are willing to admit. It is a strange piece of medical ethics, to say that "when the assistant in his turn requires assistance, he will consider thirty or forty pounds sufficient " Of course he would; ten, or twenty, were it the custom. But is it right that it should be so ?

We all like to purchase in the cheapest market, professional or non-professional. I hold it to be absurd for any one in the garb of common sense to put the question in such a manner, becatuse it is overlooking the morality of the point. The great complaint is, the want of good and confidential assistants, and this can only be remedied by better encouragement from those who really require them.

I am happy to say that I, myself, have always obtained the salary and treatment which I asked for, without much trouble, and cannot but think that the assistant in the present day has, in a great measure, the ball at his own foot.

September, 1851 . I am, \&c.,

To the Editor of THE LANCET. A T. C.

Sir,-In the number of THE LANCET of the 13th Sept., there is a note from Mr. Spong, of Faversham, respecting the advantages reaped by medical assistants when placed under the dominion of general practitioners, and he also proceeds to extenuate the small remuneration given them, by saying that though it is not large, thirty or forty pounds a year is ample for an assistant, when these advantages are thrown into the scale. Now I do not wish to make use of any observations that may tend to acrimony or ill-feeling, nevertheless I must say, that as far as my experience has gone, and the mental sufferings which that has entailed on me, that the general conduct pursued by general practitioners to their assistants is anything but honourable to an enlightened profession; and $\mathbf{I}$ will also say that there is little to be learned by taking those assistantships. In nine cases out of ten the assistant is solely hired to attend to the pauper part of the practice, and if he dare administer drugs of an expensive character, he is either dismissed for so doing, or subject to the disapprobation of the employer, and he is thereby confined to a certain routine which neither benefits him nor those under his charge. This I have experienced over again, and $I$ also have found that instead of having, as Mr. Spong says, a well-stocked library at my command, it was quite the reverse; the library, I admit, was there in some shape or other, but the act of reading, or being found in it, endeavouring to improve the mind and store of knowledge, was looked on with dislike, and as if there was not sufficient of their business to occupy your time, and earn the paltry pittance doled out, and the morsel that was consumed. It would take up too much of your valuable space to enumerate the other vexations which a poor assistant has to endure. He is looked on as an interloper, and one whom they are obliged to keep, and not, as Mr. Spong says, in the light of a professional brother. I have been an assistant for the last six years, and I always found the salary was the same whether you had experience or not, and irrespective of your being three months or six years at the profession. Yet these are the men who are always crying out about the paltry way they are treated by boards of guardians. Surely they ought not to complain of being badly paid when they adopt the self-same system to their ill-paid and hard-worked assistants. Mr. Spong forgets that cooks and butlers frequently get twenty and forty pounds a year for their services, but this is quite sufficient, in his estimation, for junior members of the high profession he prides himself in belonging to-proh! pudor. Yet with this salary the assistant must dress as a gentleman, pay his washing-bill, work night and day, dispense and attend. midwifery, keep the books, and in some cases keep the surgery clean, and wipe and dust the bottles. It may be that some will say how unfortunate $I$ was in my selection of situations; and my reply is, that the complaints $I$ make are almost all pretty general, and I believe such treatment and remuneration drive many young men to drown their sorrow in the bottle, and render them careless as to whether they progress successfully or not in their profession. Parents and guardians, look to it before you apprentice your children or those under your charge, to the medical profession, unless you have got property to leave them independent of the tender mercies and benefits derivable from the life of a medical assistant!

Sept. 1851. I am, Sir, your obedient servant,

EXPERIENTIA

\section{THE ROYAL COLLEGE OF SURGEONS AND HOMCEOPATHY.}

[ADDITIONAL CORRESPONDENCE BETWEEN DR. J. C. HALL, OF SHEFFIELD, AND THE COTNOII OF THE ROXAL COLLEGE OF SURGEONS OF ENGLAND.

\section{To the Editor of THE LANCET.}

DR. J. C. $H_{\Delta L L}$ present his compliments to the Editor, and requests the publication of the enclosed letter, which he has addressed to the Council of the Royal College of Surgeons of England, in consequence of his not having received, as yet, any satisfactory reply to his former letter respecting those members of the College who, by either practising homœopathy, or by meeting practitioners of homœopathy in consultation, have reudered themselves, in the terns of its by-laws, "disgraceful to the College."

Surrey-street, Sheffield, Sept. 27, 1851.

To the Council of the Royal College of Surgeons of England. Sheffield, Sept. 27,1851

Gentremen, - Some weeks ago, through the President of our College, I ventured to address a letter to you, asking what steps you intended to take respecting those fellows and nembers of the Royal College of Surgeons of Eugland, who, by practising as homeopaths, have virtually excluded themselves 